\title{
Diagnostic and prognostic performances of serum procalcitonin in patients with bloodstream infections: A parallel, case-control study comprising adults and elderly
}

\author{
Behrooz Shokouhi ${ }^{1}$, Kaveh Rezael Bookani ${ }^{2}$, Hossein Ghasemi ${ }^{3}$, Mahmoud Khalouel ${ }^{4}$, Naghmeh Javanshir Rezaei ${ }^{5}$, \\ Simin Mirakhor Samani ${ }^{6 *}$
}

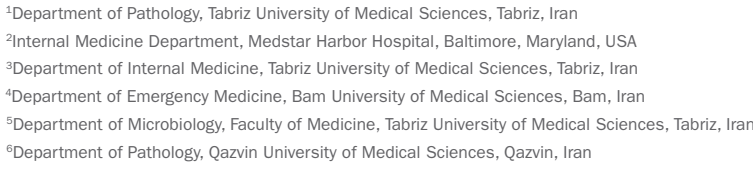

Study conducted at the Department of Pathology, Qazvin University of Medical Sciences, Qazvin, Iran

Article received: $11 / 26 / 2016$ Accepted for publication: $12 / 4 / 2016$

*Correspondence: Department of Pathology, Qazvin University of Medical Sciences Qazvin - Iran Postal code: 212234 samanilab@yahoo.com

\section{SUMMARY}

Objective: To examine the diagnostic and prognostic performances of serum procalcitonin (PCT) in adult and elderly patients with bloodstream infections (BSIs). Method: A total of 176 patients with culture-proven BSIs and 200 healthy counterparts were studied prospectively. Participants were studied in two adult (age $\leq 65$ years, $n=92$ ) and elderly (age $>65$ years, $n=84$ ) groups. Admission serum PCT level was measured using a standard enzyme-linked immunosorbent assay (ELISA) technique.

Results: The mean serum PCT level (in $\mathrm{ng} / \mathrm{mL}$ ) was significantly higher in cases than in controls ( 0.18 vs. $0.07, \mathrm{p}=0.01$ in adults; 0.20 vs. $0.07, \mathrm{p}=0.002$ in elderly). At cut-off values of $0.09 \mathrm{ng} / \mathrm{mL}$ in adults and $0.08 \mathrm{ng} / \mathrm{mL}$ in the elderly, the corresponding sensitivity and specificity were 82.6 and $82.0 \%$ in adults, and 69.1 and $70.0 \%$ in elderly, respectively. At a cut-off value of $0.2 \mathrm{ng} / \mathrm{mL}$, the sensitivity and specificity of serum PCT in predicting 28-day mortality were 81 and $81.7 \%$ in adults, and 75 and $80.4 \%$ in elderly, respectively.

Conclusion: Although admission serum PCT is a sensitive and specific biomarker for the diagnosis of BSIs in patients younger than 65 years old, its short-term prognostic value is comparable between adults and the elderly.

Keywords: procalcitonin, bloodstream infections, age.

\section{INTRODUCTION}

Bloodstream infections (BSIs) are very common and potentially lethal, particularly in the elderly and among immunocompromised patients. ${ }^{1}$ Early diagnosis and implementation of an appropriately therapy, however, could reduce the morbidity and mortality associated with BSIs. ${ }^{2}$

Blood culture is generally considered the method of choice for the diagnosis of sepsis, but it is time-consuming, i.e., results are typically available only after $12-48$ hours. In addition, skin contamination may mislead physicians in some cases. ${ }^{3,4}$ As a result, since uncertain exclusion of sepsis from a differential diagnosis list in acute stages is risky, the administration of empiric antibiotics is usually inevitable and has untoward consequences. ${ }^{5}$
To preclude this shortcoming, researchers have tried to find an accurate test for the diagnosis of BSI at early stages. In 1993, Assicot et al. ${ }^{6}$ found that serum procalcitonin (PCT) levels rise when sepsis or other significant bacterial infections occur. Soon later, several studies suggested that serum PCT could be used as a sensitive biomarker to detect or rule out BSIs in patients with suspected bacterial infections and systemic inflammatory response syndrome (SIRS). ${ }^{7,8}$ Despite many studies and even some meta-analyses, the topic is still a matter of heated debate due to inconsistent findings. ${ }^{9-14}$ Such heterogeneity might arise from using different subgroups of patients, ${ }^{9}$ inconsistency in defining bacteremia and septicemia ${ }^{10-12}$ and severe methodological flaws (such as using a small sample size and problematic grouping). ${ }^{13}$ 
A factor that has been neglected in previous studies is the patients' age. ${ }^{12}$ This may also affect the prognostic value of PCT in patients with BSIs. ${ }^{15}$ As to address this limitation, we have performed this study to examine diagnostic and prognostic values of serum PCT in the management of adult and elderly patients with BSIs, separately.

\section{Method}

From April 2013 through June 2016, a total of 206 adult hospitalized patients with culture-proven BSIs and 200 healthy random volunteers from patients' families were prospectively enrolled into this case-control study. Patients with renal disease/malignancy $(\mathrm{n}=14)$, immune problems $(n=6)$, recent trauma/surgery $(n=6)$ and a history of recent antibiotic therapy for more than 48 hours $(n=4)$ were excluded, yielding 176 patients in the case group for final analysis (Figure 1). The ethics committee of our university approved our study and informed written consents were obtained from all of the participants.

Participants were divided into groups based on age, namely adults (up to 65 years) and elderly (65 plus years), with both case and control sets as follows: 92 cases vs. 100 controls and 84 cases vs. 100 controls, respectively.

A case with BSI (bacteremia or sepsis) was reported when any pathogenic bacterial species excluding coagulase- -negative staphylococci, aerobic and anaerobic diphtheroids, Micrococcus species, and Bacillus species ${ }^{16}$ was recovered in 1 or 2 sets of aerobic and anaerobic blood cultures.

Bacteremia was defined as the presence of viable bacteria in the blood; and sepsis was defined when the bacteremia was accompanied by the systemic inflammatory response syndrome (SIRS) as recognized by the presence of at least two of the following: (i) body temperature $>38^{\circ} \mathrm{C}$ or $<36^{\circ} \mathrm{C}$, (ii) heart rate $>90$ beats $/ \mathrm{min}$, (iii) respiratory rate $>20$ breaths $/ \mathrm{min}$ or $\mathrm{PaCO}_{2}<32 \mathrm{mmHg}$, and (iv) white blood cell count $>12,000$ cells $/ \mathrm{mm}^{3},<4,000$ cells $/ \mathrm{mm}^{3}$, or $>10 \%$ band. ${ }^{17}$ Most probable sources of BSIs and the types of isolated microorganisms were also reported.

The admission serum PCT level was measured in $\mathrm{ng} / \mathrm{mL}$ with enzyme-linked immunosorbent assay (ELISA) using a standard autoanalyzer (Elecsys 2010, Roche, Switzerland) according to the manufacturer's guideline.

All patients were followed up for 28 days and the prognostic ability of PCT for predicting 28-day mortality was also examined.

\section{Statistical analysis}

The statistical analyses were performed using the SPSS software version 22.0 (IBM Inc., USA). A normal distribution of quantitative data was assured using the Kol-

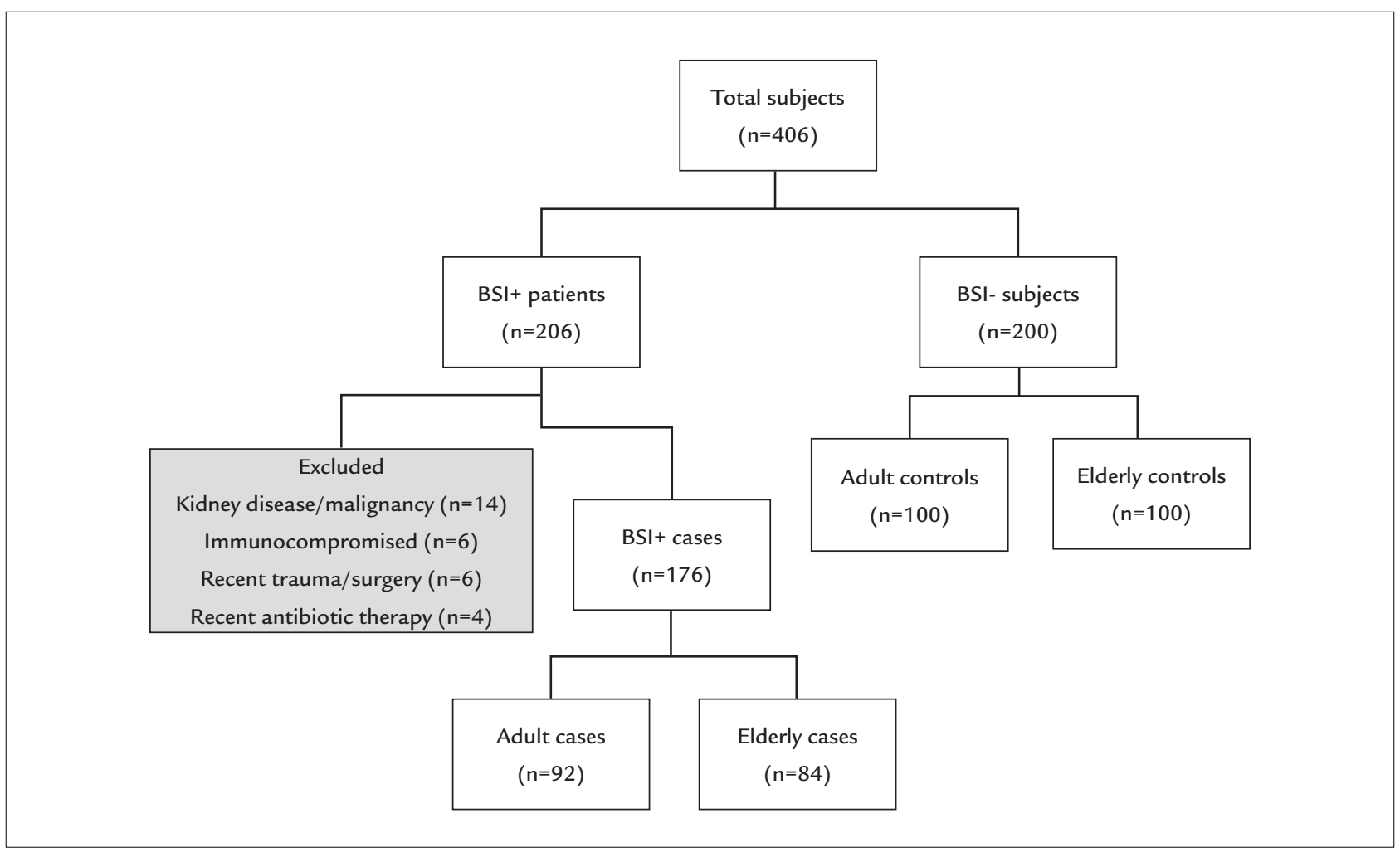

FIGURE 1 Flowchart of case and control study groups. 
mogorov-Smirnov test. The quantitative data were presented as mean \pm standard deviation or mean (standard error of the mean). Independent samples t-test and the Chi-square test were used for comparisons. The Pearson coefficient ( $r$ ) was employed to assess correlations. Receiver operator characteristic (ROC) curves were plotted to detect area under the curve (AUC) and optimal cut-off levels. A p-value of less than 0.05 (two-tailed) was considered statistically significant.

\section{Results}

Demographics of the study population in two adult and elderly groups are summarized and compared between cases and controls in Table 1. Accordingly, the groups were comparable in terms of sex and age of participants.

Sepsis was diagnosed in 42 patients (45.7\%) in the adult group and in 44 patients $(52.4 \%)$ in the elderly group. Within a 28-day follow-up time, 21 patients (22.8\%) died in the adult group and 28 patients $(33.3 \%)$ died in the elderly group.

Most probable sources and microbial etiologies of BSI in the case groups are shown in Table 2. Accordingly, both in the adult and elderly groups, urinary tract and respiratory infections were the most frequent possible sources of BSIs and Staphylococcus aureus and E. coli were the most commonly isolated bacteria, respectively.

There was no significant difference between males and females for the mean serum PCT level $(0.13[0.02] \mathrm{ng} / \mathrm{mL}$ vs. $0.18[0.03] \mathrm{ng} / \mathrm{mL}$, respectively; $\mathrm{p}=0.18)$. Patients' age and serum PCT level did not correlate significantly in the case groups $(\mathrm{r}=0.5, \mathrm{p}=0.60)$. No significant correlation was found between serum procalcitonin level and age in adult $(\mathrm{r}=0.2, \mathrm{p}=0.19)$ or elderly $(\mathrm{r}=0.02, \mathrm{p}=0.91)$ groups.

In both the adult and elderly groups, mean serum PCT levels were significantly higher in cases than in controls $(\mathrm{p}=0.01$ and 0.002 , respectively). Between patients in adult and elderly groups, however, no significant difference was found for the mean serum procalcitonin level $(\mathrm{p}=0.54)$.

The AUC of serum PCT level for predicting BSI was 0.81 (95\% confidence interval [95CI] 0.71-0.91; $\mathrm{p}<0.001$ ) in the adult group and 0.73 (95CI $0.63-0.84 ; \mathrm{p}<0.001$ ) in the elderly group. Accordingly, the optimal cut-off level of serum PCT was $0.09 \mathrm{ng} / \mathrm{mL}$ (sensitivity, $82.6 \%$; specificity, $82.0 \%$ ) in the adult group and $0.08 \mathrm{ng} / \mathrm{mL}$ (sensitivity, $69.1 \%$; specificity, $70.0 \%$ ) in the elderly group.

In both the adult and elderly groups, mean serum PCT levels were significantly higher in dead versus surviving patients after 28 days ( $\mathrm{p}<0.001$ for both).

TABLE 1 Demographic data of the study population.

\begin{tabular}{|c|c|c|c|c|c|c|c|}
\hline \multirow[t]{2}{*}{ Variable } & \multicolumn{3}{|c|}{ Adults } & \multirow[t]{2}{*}{$\mathrm{p}$-value } & \multicolumn{2}{|l|}{ Elderly } & \multirow[t]{2}{*}{ p-value } \\
\hline & & Cases $(n=92)$ & Controls $(n=100)$ & & Cases $(n=84)$ & Controls $(n=100)$ & \\
\hline \multirow[t]{2}{*}{ Sex } & Male & $54(58.7)$ & $56(56)$ & 0.79 & $50(59.5)$ & $56(56)$ & 0.73 \\
\hline & Female & $38(41.3)$ & $44(44)$ & & $34(40.5)$ & $44(44)$ & \\
\hline Age (y) & & $42.96 \pm 11.16(19-63)$ & $44.74 \pm 12.63(23-65)$ & 0.47 & $74.14 \pm 7.11(66-90)$ & $72.18 \pm 5.86(66-91)$ & 0.15 \\
\hline
\end{tabular}

Data are presented as frequency (\%) or mean \pm standard deviation (minimum-maximum).

TABLE 2 Probable sources and etiologies of bloodstream infection in adult and elderly patients.

\begin{tabular}{|c|c|c|c|}
\hline \multirow[t]{2}{*}{ Variable } & & \multicolumn{2}{|l|}{ Groups } \\
\hline & & Adults $(n=92)$ & Elderly $(n=84)$ \\
\hline \multirow[t]{5}{*}{ Source of infection } & Urinary tract & $38(41.3)$ & $32(38.1)$ \\
\hline & Respiratory system & $22(23.9)$ & $24(28.6)$ \\
\hline & Abdomen & $14(15.2)$ & $11(13.1)$ \\
\hline & Neuromeningeal & $3(3.3)$ & $4(4.8)$ \\
\hline & Multiple & $15(16.3)$ & $13(15.5)$ \\
\hline \multirow[t]{6}{*}{ Bacteria } & Staphylococcus aureus & $44(47.8)$ & $41(48.8)$ \\
\hline & E. coli & $40(43.5)$ & $37(44)$ \\
\hline & Klebsiella & $3(3.3)$ & $0(0)$ \\
\hline & Enterobacter & $2(2.2)$ & $2(2.4)$ \\
\hline & Pseudomonas & $1(1.1)$ & $0(0)$ \\
\hline & Miscellaneous & $2(1.1)$ & $4(4.8)$ \\
\hline
\end{tabular}

Data are presented as frequency (\%). 
The AUC of serum PCT level for predicting 28-day mortality was 0.82 (95\% confidence interval [95CI] 0.70-0.94; $\mathrm{p}<0.001)$ in adults and 0.83 (95CI 0.73-0.92; $\mathrm{p}<0.001)$ in the elderly. Accordingly, the optimal cut-off level of serum PCT was $0.2 \mathrm{ng} / \mathrm{mL}$ in both the adult and elderly groups, with a sensitivity of 81 and $75 \%$ and specificity of 81.7 and $80.4 \%$, respectively.

\section{Discussion}

Conventional strategies such as using clinical symptoms and biological markers of inflammation, e.g. leukocytes and C-reactive protein, have had poor diagnostic value to detect or rule out bacteremia and sepsis in previous reports, with an estimated false-negative rate of $15-50 \% .{ }^{1,18}$

In normal conditions, serum PCT is produced by the C-cells in the thyroid gland and all is cleaved to calcitonin, catacalcin and an $\mathrm{N}$-terminal residue. During clinically significant infections such as bacteremia and sepsis, however, the serum level of PCT rises dramatically. Although the exact source of this acute-phase reactant protein is not known, it is thought to be related to extra-thyroid tissues, because patients with previous total thyroidectomy still exhibit high levels of procalcitonin in their serum during infection. ${ }^{19}$

Some investigators have suggested serum PCT as an appropriate tool to differentiate bacterial infections from SIRS caused by viruses or noninfectious conditions such as trauma, burns and organ malfunction. ${ }^{20}$ Even though, for the purpose of BSI management, PCT has been found superior to conventional diagnostic methods in terms of test speed and accuracy in several studies, there is still no general consensus in this regard or in suggesting a widely accepted cut-off value despite the availability of several case-control studies and large meta-analyses. ${ }^{9-14}$ For example, in a study by Liaudat et al. ${ }^{21}$ that included 50 hospitalized bacteremic patients and 150 controls, at cut-off values of 0.5 and $0.2 \mathrm{ng} / \mathrm{mL}$ the sensitivity and specificity of PCT to detect BSIs were $56-92 \%$ and $83-43 \%$, respectively. Sudhir et al. ${ }^{1}$ included 100 patients with sepsis in their study and reported a high sensitivity value (94\%) for serum PCT to detect BSIs. In a recent study, Wang et al. ${ }^{22}$ used serum PCT for the diagnosis of BSIs in a retrospective design. The best cut-off value was reported at $0.80 \mathrm{ng} / \mathrm{mL}$, with a sensitivity and specificity of 83 and $65 \%$, respectively. They suggested serum PCT as a reliable marker to exclude bacteremia in patients with suspected BSIs. In another series by Riedel et al. ${ }^{23}$ comprising 295 patients with symptoms suggestive of systemic infection and 16 patients with definite diagnosis of BSIs, the sensitivity and specificity of PCT assay with a calcu- lated threshold of $0.1475 \mathrm{ng} / \mathrm{mL}$ to detect BSIs were 75 and $79 \%$, respectively. Accordingly, they suggested PCT as a useful marker to rule out sepsis and systemic inflammation in emergency departments. In other studies, ${ }^{24,25}$ the suggested optimal cut-off points for serum PCT varied between 0.1 to $2.0 \mathrm{ng} / \mathrm{mL}$, with sensitivity and specificity values ranging from 35 to $97 \%$ and 78 to $99 \%$, respectively. In a recent meta-analysis by Hoeboer et al., ${ }^{14}$ the diagnostic accuracy of serum procalcitonin for bacteremia was examined. In all, 58 studies including 3,420 patients with bacteremia were reviewed. At a cut-off value of $0.5 \mathrm{ng} / \mathrm{mL}$, the overall sensitivity and specificity of this biomarker were 76 and $69 \%$, respectively. The authors, however, concluded that due to the heterogeneity of available studies, further research is needed in this regard.

According to a report, age and past medical history are two important parameters that might contribute to such heterogeneity ${ }^{26}$ For instance, it has been shown that false-positive results of PCT testing are frequent among patients with renal problems. ${ }^{23}$

To exclude these potential confounding factors, we only included patients with intact renal function and normal immune system. In addition, the diagnostic performance of serum PCT was examined separately in adults (18-65 years) and the elderly (over 65 years) in our study. Based on our findings, at optimal cut-off values of $0.09 \mathrm{ng} / \mathrm{mL}$ for adults and $0.08 \mathrm{ng} / \mathrm{mL}$ for the elderly, serum PCT was accompanied with a better diagnostic performance in the former (sensitivity and specificity of 82.6 and $82 \%$ in adults versus 69.1 and $70 \%$ in the elderly, respectively).

The usefulness of serum PCT to manage patients with suspected BSIs has rarely been examined in the elderly. ${ }^{27}$ It is still not clear how the age of patients may affect serum levels of PCT during BSIs. In a recent study by Stucker et al., ${ }^{28}$ and, in accordance with our findings, the authors concluded that serum PCT should not be considered a reliable indicator of BSIs among the elderly.

Whenever sepsis occurs, the innate immune response is activated by releasing various cytokines such as interleukins 1, 6 and 8, tumor necrosis factor- $\alpha$, and interferon- $\gamma$ from the endothelial and epithelial cells and macrophages. ${ }^{29}$ When this reaction is extensive and diffused, endothelial cell damage may ensue, which in turn may cause hemodynamic changes and organ failure. ${ }^{27}$ Among the elderly and immunocompromised patients, however, the classic signs of sepsis may be missing because of decreased inflammatory responses in such patients. ${ }^{30}$ In addition, it has been shown that serum PCT levels correlate positively with the severity of inflammatory responses to infections. ${ }^{31}$ This can explain why serum procalcitonin is a more reli- 
able indicator of BSIs under 65 years of age. To the best of the authors' knowledge, ours is the first study in the literature that assesses the diagnostic performance of serum PCT among adults and the elderly in parallel.

It should be kept in mind that BSIs are more common among the elderly. Besides a high prevalence, comorbid chronic diseases that usually develop with advanced age, a compromised immune system, inability to communicate adequately with the physician, and nonspecific signs and symptoms of infection further deteriorate the prognosis of BSIs in the elderly. ${ }^{8}$ So, as a second goal, we examined the prognostic utility of serum PCT in predicting 28-day mortality among adult and elderly patients. In conformity with some recent studies, ${ }^{15,32-34}$ we showed that, at a cut-off value of $0.2 \mathrm{ng} / \mathrm{mL}$ in both groups, this biomarker is a good indicator of short-term mortality (sensitivity and specificity of around $80 \%$ ). Again, our study is the first in the medical literature to report an almost equal performance of serum PCT to predict mortality in both adult and the elderly patients with BSIs.

In addition to its high accuracy to detect BSIs, serum PCT has been suggested as an inexpensive biomarker that is not affected by viral infections or inflammatory reactions of non-infectious origin. It is capable to detect bacteremia rapidly $(<1$ hour) and has an established prognostic significance as well as longer half-life in the systemic circulation (25-30 h) compared to other conventionally used cytokines. In addition, analyzing the serum level of this biomarker requires only a small amount of blood sample. . $33,35,36^{2}$

Despite significant advantages of our study, such as using matching groups of patients and controls as to age, past medical history and ethnicity, ${ }^{1}$ a state-of-the-art, up-to-date technology to determine serum PCT levels, culture-proven final diagnosis in all participants, and the study on a rather large number of patients, it may be found limited in terms of not incorporating the severity of BSIs in the final conclusion.

Finally, since in the elderly the studied variable is prognostic rather than diagnostic, it is likely that the rise of procalcitonin is time-dependent in this age group. So, further longitudinal studies should be considered in the future.

\section{Conclusion}

We showed that serum PCT can be used more reliably in adults than in the elderly with suspected BSIs. The short-term prognostic value of this biomarker, however, does not differ considerably between old and younger patients.

\section{REFERENCES}

1. Sudhir U, Venkatachalaiah RK, Kumar TA, Rao MY, Kempegowda P. Significance of serum procalcitonin in sepsis. Indian J Crit Care Med. 2011; 15(1):1-5.

2. Jaimes F, Arango C, Ruiz G, Cuervo J, Botero J, Velez G, et al. Predicting bacteremia at the bedside. Clin Infect Dis. 2004; 38(3):357-62.

3. Vorwerk C, Loryman B, Coats TJ, Stephenson JA, Gray LD, Reddy G, et al. Prediction of mortality in adult emergency department patients with sepsis. Emerg Med J. 2009; 26(4):254-8.

4. Kassis C, Rangaraj G, Jiang Y, Hachem RY, Raad I. Differentiating culture samples representing coagulase-negative staphylococcal bacteremia from those representing contamination by use of time-to-positivity and quantitative blood culture methods. J Clin Microbiol. 2009; 47(10):3255-60.

5. Riedel S, Bourbeau P, Swartz B, Brecher S, Carroll KC, Stamper PD, et al. Timing of specimen collection for blood cultures from febrile patients with bacteremia. J Clin Microbiol. 2008; 46(4):1381-5.

6. Assicot M, Gendrel D, Carsin H, Raymond J, Guilbaud J, Bohuon C. High serum procalcitonin concentrations in patients with sepsis and infection. Lancet. 1993; 341(8844):515-8.

7. Shen CJ, Wu MS, Lin KH, Lin WL, Chen HC, Wu JY, et al. The use of procalcitonin in the diagnosis of bone and joint infection: a systemic review and meta-analysis. Eur J Clin Microbiol Infect Dis. 2013; 32(6):807-14.

8. Yilmaz H, Duran L, Yanik K, Altuntaş M, Sünbül M. Differences in the effectiveness of serum biomarkers for the diagnosis of bacterial infections in adult and elderly patients admitted to the emergency department. Turk J Med Sci. 2015; 45(3):553-7.

9. Tang BM, Eslick GD, Craig JC, McLean AS. Accuracy of procalcitonin for sepsis diagnosis in critically ill patients: systematic review and meta-analysis. Lancet Infect Dis. 2007; 7(3):210-7.

10. Wacker C, Prkno A, Brunkhorst FM, Schlattmann P. Procalcitonin as a diagnostic marker for sepsis: a systematic review and meta-analysis. Lancet Infect Dis. 2013; 13(5):426-35.

11. Simon L, Gauvin F, Amre DK, Saint-Louis P, Lacroix J. Serum procalcitonin and C-reactive protein levels as markers of bacterial infection: a systematic review and meta-analysis. Clin Infect Dis. 2004; 39(2):206-17.

12. Lee SH, Chan RC, Wu JY, Chen HW, Chang SS, Lee CC. Diagnostic value of procalcitonin for bacterial infection in elderly patients - a systemic review and meta-analysis. Int J Clin Pract. 2013; 67(12):1350-7.

13. Jones AE, Fiechtl JF, Brown MD, Ballew JJ, Kline JA. Procalcitonin test in the diagnosis of bacteremia: a meta-analysis. Ann Emerg Med. 2007; 50(1):34-41

14. Hoeboer SH, van der Geest PJ, Nieboer D, Groeneveld AB. The diagnostic accuracy of procalcitonin for bacteraemia: a systematic review and metaanalysis. Clin Microbiol Infect. 2015; 21(5):474-81.

15. Liu D, Su L, Han G, Yan P, Xie L. Prognostic value of procalcitonin in adult patients with sepsis: a systematic review and meta-analysis. PLoS One. 2015; 10(6):e0129450.

16. Richter SS, Beekmann SE, Croco JL, Diekema DJ, Koontz FP, Pfaller MA, et al. Minimizing the workup of blood culture contaminants: implementation and evaluation of a laboratory-based algorithm. J Clin Microbiol. 2002; 40(7):2437-44

17. Chanmugam AS, Rothman R, Desai SV, Putman SB. Infectious disease emergencies. Oxford; New York: Oxford University Press; 2016.

18. Bleeker-Rovers CP, Vos FJ, de Kleijn EM, Mudde AH, Dofferhoff TS, Richter $\mathrm{C}$, et al. A prospective multicenter study on fever of unknown origin: the yield of a structured diagnostic protocol. Medicine (Baltimore). 2007; 86(1):26-38.

19. Uusitalo-Seppälä R, Koskinen P, Leino A, Peuravuori H, Vahlberg T, Rintala EM. Early detection of severe sepsis in the emergency room: diagnostic value of plasma C-reactive protein, procalcitonin, and interleukin-6. Scand J Infect Dis. 2011; 43(11-12):883-90.

20. Fraunberger P, Wang Y, Holler E, Parhofer KG, Nagel D, Walli AK, et al. Prognostic value of interleukin 6, procalcitonin, and C-reactive protein levels in intensive care unit patients during first increase of fever. Shock. 2006; 26(1):10-2.

21. Liaudat S, Dayer E, Praz G, Bille J, Troillet N. Usefulness of procalcitonin serum level for the diagnosis of bacteremia. Eur J Clin Microbiol Infect Dis. 2001; 20(8):524-7.

22. Wang H, Yin F, Shen DX, Zhang YJ, Luo YP, Liu CJ, et al. Predictive value of procalcitonin for excluding bloodstream infection: results of a retrospective study and utility of a rapid, quantitative test for procalcitonin. J Int Med Res. 2013; 41(5):1671-81. 
23. Riedel S, Melendez JH, An AT, Rosenbaum JE, Zenilman JM. Procalcitonin as a marker for the detection of bacteremia and sepsis in the emergency department. Am J Clin Pathol. 2011; 135(2):182-9.

24. Cornelissen CG, Frechen DA, Schreiner K, Marx N, Krüger S. Inflammatory parameters and prediction of prognosis in infective endocarditis. BMC Infect Dis. 2013; 13:272.

25. Mencacci A, Leli C, Cardaccia A, Meucci M, Moretti A, D’Alò F, et al. Procalcitonin predicts real-time PCR results in blood samples from patients with suspected sepsis. PLoS One. 2012; 7(12):e53279.

26. Caterino JM, Scheatzle MD, Forbes ML, D'Antonio JA. Bacteremic elder emergency department patients: procalcitonin and white count. Acad Emerg Med. 2004; 11(4):393-6

27. Lai CC, Chen SY, Wang CY, Wang JY, Su CP, Liao CH, et al. Diagnostic value of procalcitonin for bacterial infection in elderly patients in the emergency department. J Am Geriatr Soc. 2010; 58(3):518-22.

28. Stucker F, Herrmann F, Graf JD, Michel JP, Krause KH, Gavazzi G. Procalcitonin and infection in elderly patients. J Am Geriatr Soc. 2005; 53(8):1392-5.

29. Russell JA. Management of sepsis. N Engl J Med. 2006; 355(16):1699-713.

30. Steichen O, Bouvard E, Grateau G, Bailleul S, Capeau J, Lefevre G. Diagnostic value of procalcitonin in acutely hospitalized elderly patients. Eur J Clin Microbiol Infect Dis. 2009; 28(12):1471-6.
31. Brunkhorst FM, Wegscheider K, Forycki ZF, Brunkhorst R. Procalcitonin for early diagnosis and differentiation of SIRS, sepsis, severe sepsis, and septic shock. Intensive Care Med. 2000; 26(Suppl 2):S148-52.

32. Azevedo JR, Torres OJ, Czeczko NG, Tuon FF, Nassif PA, Souza GD Procalcitonin as a prognostic biomarker of severe sepsis and septic shock. Rev Col Bras Cir. 2012; 39(6):456-61.

33. Kibe S, Adams K,Barlow G. Diagnostic and prognostic biomarkers of sepsis in critical care. J Antimicrob Chemother. 2011; 66 Suppl 2:ii33-40.

34. Rajkumari N, Mathur P, Sharma S, Gupta B, Bhoi S, Misra MC. Procalcitonin as a predictor of sepsis and outcome in severe trauma patients: a prospective study. J Lab Physicians. 2013; 5(2):100-8.

35. Heper Y, Akalin EH, Mistik R, Akgöz S, Töre O, Göral G, et al. Evaluation of serum C-reactive protein, procalcitonin, tumor necrosis factor alpha, and interleukin-10 levels as diagnostic and prognostic parameters in patients with community-acquired sepsis, severe sepsis, and septic shock. Eur J Clin Microbiol Infect Dis. 2006; 25(8):481-91.

36. Viallon A, Guyomarc'h S, Marjollet O, Berger C, Carricajo A, Robert F, et al. Can emergency physicians identify a high mortality subgroup of patients with sepsis: role of procalcitonin. Eur J Emerg Med. 2008; 15(1):26-33. 